\title{
THE PARTICIPATION OF PEOPLE IN DEVELOPING AGRICULTURE VALUE CHAIN OF WILD PORK AND WILD PIGS IN THE NORTH OF VIETNAM
}

\author{
Bui Thi Thom', Dinh Tran Ngoc Huy ${ }^{2 *}$, Nguyen Thi Hoa ${ }^{3}$, Bui Thi Suu ${ }^{4}$ \\ ${ }^{I}$ Thai Nguyen University of Agriculture and Forestry, Vietnam; \\ 2*Banking University HCMC, Ho Chi Minh city Vietnam - International University of Japan, Japan; \\ ${ }^{3}$ Thu Dau Mot Unievrsity, Binh Duong, Vietnam; \\ ${ }^{4}$ Tay Bac University, Quyet Tam Ward, Son LA city, Son La Province, Vietnam; \\ *Corresponding Author Dinh Tran Ngoc Huy, e-mail: dtnhuy.2010@gmail.com;
}

Received June 2021; Accepted July 2021; Published August 2021;

DOI: https://doi.org/10.31407/ijees11.411

\begin{abstract}
Authors perform this research to study on constructing value chain of wild pork and wild pigs in the northern region of Vietnam. Thuy, N.T (2021) presented the analysis results show that factors including: income, natural conditions, loan capital, market have a great impact on the level of people's participation. Since then, the article has suggested some solutions to improve people's participation in agricultural value chain development of wild pigs and wild pork. Thom, BT., \& Huy, D.T.N (2021) stated Feeding wild pigs and managing wild pork meat quality is meaningful in Vietnam, esp. In Thai Nguyen province as pork products can offer variety of tastes due to food processing and suitable for Vietnamese tastes and can export to the world widely. Feeding wild board in different environment also affect quality of wild pork meat, for example in US, Brazil or In Vietnam. It is in the study we will make comparison to wild pork meat in China and Thailand and suggest to enhance vale chain linkage of wild pork and wild pigs to enhance exporting markets. Last but not least, better value chain linkage can be enhanced through reducing transaction costs from wild pig farming to factories and producing wild pork meat following European standards or GlobalGAP or VIETGAP.
\end{abstract}

Key words: wild pork, wild pigs, agriculture value chain, linkage, Vietnam, northern region 